\title{
Guidelines for the management of
}

\section{work-related asthma}

\author{
X. Baur, T. Sigsgaard, T.B. Aasen, P.S. Burge, D. Heederik, P. Henneberger, \\ P. Maestrelli, J. Rooyackers, V. Schlünssen, O. Vandenplas and D. Wilken on behalf of \\ the ERS Task Force on the Management of Work-related Asthma
}

ABSTRACT: Work-related asthma, which includes occupational asthma and work-aggravated asthma, has become one of the most prevalent occupational lung diseases. These guidelines aim to upgrade occupational health standards, contribute importantly to transnational legal harmonisation and reduce the high socio-economic burden caused by this disorder.

A systematic literature search related to five key questions was performed: diagnostics; risk factors; outcome of management options; medical screening and surveillance; controlling exposure for primary prevention. Each of the 1,329 retrieved papers was reviewed by two experts, followed by Scottish Intercollegiate Guidelines Network grading, and formulation of statements graded according to the Royal College of General Practitioners' three-star system.

Recommendations were made on the basis of the evidence-based statements, which comprise the following major evidence-based strategic points. 1) A comprehensive diagnostic approach considering the individual specific aspects is recommended. 2) Early recognition and diagnosis is necessary for timely and appropriate preventative measures. 3) A stratified medical screening strategy and surveillance programme should be applied to at-risk workers. 4) Whenever possible, removing exposure to the causative agent should be achieved, as it leads to the best health outcome. If this is not possible, reduction is the second best option, whereas respirators are of limited value. 5) Exposure elimination should be the preferred primary prevention approach.

KEYWORDS: Diagnostics, occupational asthma, occupational exposure, prevention, risk factors, surveillance

\section{INTRODUCTION}

\section{What is work-related asthma?}

Work-related asthma refers to occupational asthma and work-aggravated asthma (fig. 1). Occupational asthma is a disease characterised by variable airflow limitation and/or hyperresponsiveness associated with inflammation due to causes and conditions attributable to a particular occupational environment and not to stimuli encountered outside the workplace [1]. Occupational asthma involves: immunoglobulin (Ig)E-mediated asthma after a latency period; irritant asthma with or without a latency period, including reactive airways dysfunction syndrome, which results from high exposure(s); and asthma due to specific occupational agents with unknown pathomechanisms, which also frequently show a latency period (fig. 1) [2].

Work-aggravated asthma is characterised by worsening of pre-existing asthma (e.g. shown by a decrease of forced expiratory volume in $1 \mathrm{~s}$ (FEV1) or methacholine provocative dose causing a 20\% fall in FEV1 (PD20), or increases in airway resistance, asthma medications or frequency and/ or severity of asthma attacks) due to causes and conditions attributable to a particular occupational environment and not to stimuli encountered outside the workplace. The worker has a concurrent

For editorial comments see page 518 .

The June 2012 issue of the European Respiratory Review will feature a series of supporting articles from the ERS Task Force on the Management of Work-related Asthma.

This article has supplementary material accessible from www.erj.ersjournals.com

AFFILIATIONS

Author affiliation details and a list of the Task Force members can be found in the Acknowledgements section.

CORRESPONDENCE

$X$. Baur

Institute for Occupational and

Maritime Medicine

University Medical Center

Hamburg-Eppendorf

Seewartenstrasse 10

D-20459 Hamburg

Germany

E-mail: baur@uke.de

Received:

June 062011

Accepted after revision:

Nov 282011 


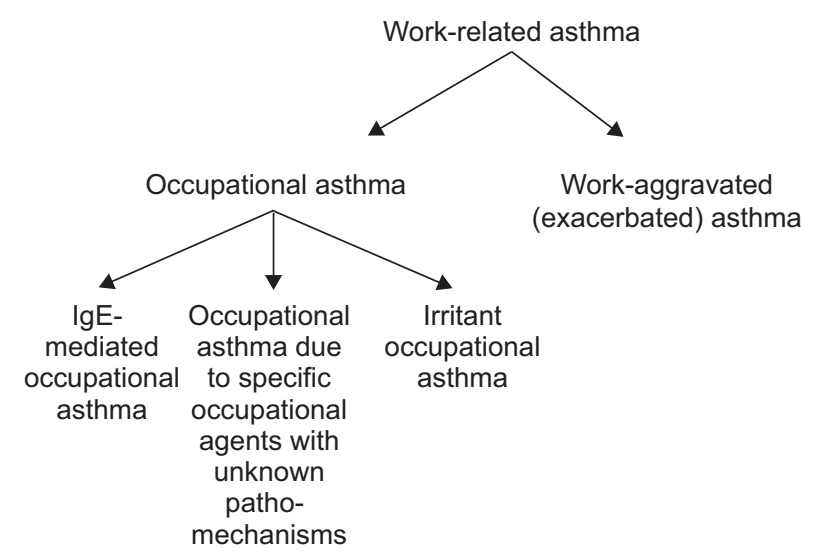

FIGURE 1. Work-related asthma and its subgroups. IgE: immunoglobulin E.

history of asthma that was not induced by an exposure in the workplace. Aggravation is typically due to an occupational irritant (e.g. non-sensitising fumes) [3].

There are also workers with pre-existing asthma who, after a latent interval, experience a worsening of their asthma with regular daily exposure to agents that can cause IgE-mediated allergies in others. These workers are included in the occupational asthma or work-aggravated asthma groups, depending on national regulations and related case definitions.

Some occupational exposures that are potential causes of occupational asthma, particularly high concentrations of welding fumes, isocyanates, potroom and a range of other occupational noxious exposures (e.g. aluminium, cadmium, metals, ammonia, environmental tobacco smoke, wood dust, cotton and endotoxin), have also been reported to cause chronic obstructive pulmonary disease (COPD), without any acute symptoms to suggest asthma [4-11]. Obviously, some workers with symptoms suggestive of occupational asthma develop predominantly fixed airflow obstruction more suggestive of COPD [12]. Some of these may improve over long periods away from exposure, but some do not. The pathology of these workers developing predominantly fixed airflow obstruction is unknown. Furthermore, symptoms in asthmatics that do not improve during weekends or holidays may indicate a progressive course, and may coincide with symptoms and persistent airway obstruction typical of COPD patients [12]. Asthma and COPD have been interpreted as different physiological conditions [6] or different expressions of the same airway disease [5]. Respective clinical findings and entity consideration also apply to occupational obstructive airways disorders and there is evidence for a group with changing diagnoses, as well as some overlap between occupational asthma and occupational COPD [3, 13-18].

Recently, BLANC and TORÉN [19] reviewed the literature and estimated the population-attributable risk of COPD to be $15 \%$, which indicates that the occupational causes of these disorders are generally overlooked in routine diagnostics. Misdiagnoses are mainly due to the lack of specific diagnostic tests, the absence of attacks of shortness of breath and frequent concomitant smoking habits as a confounder. SALVI and BARNES [20] reported similar figures in their review, which was mainly based upon the papers of BEHRENDT [21], LAMPREChT et al. [22], UlvesTAD et al. [23], BERGDAHL et al. [10], HNIZDO et al. [8] and WeINMANN et al. [24].

Several other conditions that have some overlap represent risk factors for occupational asthma, including eosinophilic bronchitis, asthma-like symptoms and work-related rhinitis [2].

As the aforementioned overlapping occupational disorders have not been subjected to detailed scientific investigations, these guidelines will focus on work-related asthma.

\section{Objectives and concept of these guidelines}

Work-related asthma is a preventable disease, similar to other work-related respiratory diseases such occupational COPD. Relevant legal definitions, regulations and measures for prevention, diagnosis, compensation and rehabilitation differ considerably between countries, some having lower standards than others.

These evidence-based guidelines take existing guidelines for the prevention of occupational asthma [2] into consideration, including the British Occupational Health Research Foundation (BOHRF) [25], American College of Chest Physicians (ACCP) [3], and the Agency for Healthcare Research and Quality (AHRQ) [26]. The main focus was on the answer to five key questions related to the management of occupational asthma using evidence from articles retrieved from extensive systematic searches of the literature. Papers addressing prevention, diagnostic tools and the management of work-related asthma were critically reviewed.

An initial step was to summarise the available evidence on the frequency and causes of occupational asthma in order to show the urgent need for intensified preventative efforts. $5-20 \%$ of new cases of adult asthma can be attributed to work exposure [27-29]. The annual incidence of work-related asthma, which is associated with a high rate of prolonged work disruption [2], is $\sim 50$ per million workers, with extremes up to 140 per million and even up to 1,300 per million in certain workplaces [30]. BOYD et al. [31] summarised data from Great Britain [2] and estimated an annual total cost of $£ 305-£ 2,735$ per "average" afflicted person (prices as at 2004). The costs of occupational asthma were shown to vary substantially depending on disease severity.

These guidelines are intended to supplement other work-related asthma guidelines. Management issues specific to work-related asthma in particular were considered, in contrast to asthma in general. They cover both primary and secondary prevention. Tertiary prevention, rehabilitation and compensation issues are addressed but not in detail. The guidelines have two primary audiences: 1) workers in all industrial and occupational sectors; and 2) healthcare providers and practitioners, such as occupational and primary care physicians involved in diagnosis, treatment and/or education. In addition, political parties, policy makers, industrial physicians, and worker and employer representatives with responsibility for health and safety may benefit from the guidelines. The knowledge summarised in this document might help improve company policies and legal regulations connected with work-related asthma. However, the guidelines do not focus on management tools for governmental authorities.

Further tasks are to propose evidence-based recommendations in order to extend and, if necessary, modify the available national guidelines regarding these topics. Another future aim could be the compilation of useful information, such as a legal framework for the prevention of occupational asthma in 
individual countries, in order to describe the basis for improving primary and secondary prevention. A future publication is intended to focus on this issue, and a set of cases will be prepared with the aim of comparing management and compensation systems for WRA in different countries, and providing content for leaflets to help guide different audiences.

\section{METHODS}

\section{Formulation of research questions}

An international panel of experts was convened to develop these guidelines as a Task Force of the European Respiratory Society (ERS). An initial meeting of the Task Force took place at the 2007 ERS Congress in Stockholm. A consensus was reached at this meeting on five key questions (table 1). Specific questions arising at subsequent Task Force meetings were included as ancillary questions.

\section{Literature review}

Appropriate terms were used to search Medline via PubMed (www.ncbi.nlm.nih.gov/pubmed; see table sO1 for search terms used and number of retrieved results). The database was searched by tracking the most sentinel articles forward in time. Initial searches were performed for each key question and their ancillary question. The searches were completed and included references of papers published until the end of April 2010. Case reports and non-systematic review articles were excluded; each retrieved title and, when available, abstract was independently screened by two occupational respiratory medicine specialists of each working group. Papers obviously not addressing the topic of interest were excluded. The full text versions of remaining papers were independently assessed by the two occupational respiratory medicine specialists of each working group for each question. Members of the working groups for the different key questions and ancillary questions made supplementary literature searches using Medline and their own archives of published literature. Further publications from the reference lists of the reviewed papers and of review articles were added if considered useful by the individual working group, and assessed according to the method already described. For these additional searches, the same selection criteria were applied, as described above (see table $\mathrm{sO} 2$ for the deepening search results).

\section{Quality review of the literature}

The methodological quality of each selected study was assessed independently by two reviewers and rated according to the Scottish Intercollegiate Guidelines Network (SIGN) classification [32]. Disagreements were resolved by discussion and/or consulting the whole Task Force. The evidence relevant to the two working groups on prognostic factors, surveillance and primary prevention often consisted of observational study designs. The studies were assessed for potential biases (selection, confounding, information bias), considering the sources of bias and bias minimisation strategies in either the design or analysis phase, specific to each study design. For primary prevention studies, where measurement of exposure to occupational agents plays a crucial role, the exposure assessment component was specifically considered, using criteria described in a World Health Organization working document [33] for exposure assessment studies in epidemiological surveys, and applied by LENTERS et al. [34] in a meta-analysis for asbestos.

\section{Synthesis}

The heterogeneity of the studies in the following areas prevented the use of sophisticated methods of meta-analysis for the majority of questions: study design (cross-sectional, casecontrol, longitudinal); measurement methods for disease endpoints or intermediate end-points such as sensitisation, and epidemiological end-points (repeated measurements in longitidudinal studies versus incidence data); measurement methods for the determinants considered; the statistical methods employed. Narrative summaries were written in these cases. The available evidence often consisted of a cross-sectional survey, which received relatively low SIGN scores. Study size (i.e. number of patients) was considered to give an impression of the discriminatory power of the studies (i.e. of their precision). For key question 3, study design and measurement methods of the included intervention studies were comparable and a metaanalysis could be conducted. The pooled odds ratio (based on available individual studies) was calculated for each outcome after reduction or cessation of exposure using a random-effect model because heterogeneity between studies was observed. Full details about the methodology used are given elsewhere [35].

Search results and a list of articles considered have been included in the evidence tables presented in table sO3.

\section{Strength of evidence and grading of recommendation}

The strength of the evidence for each question was graded according to the three-star system of the Royal College of General Practitioners (RCGP), which includes the quality and the quantity of the evidence [36].

The strength and clinical relevance of the recommendation was classified according to the system of the Grading of Recommendations Assessment, Development and Evaluation (GRADE) working group [37], which was adapted by the American Thoracic Society (ATS) [38]. Draft statements and recommendations were presented and discussed during Task Force meetings. Final statements and grades of recommendations were the result of consensus among Task Force members.

\section{TABLE 1 Key questions of the guidelines for the management of work-related asthma}

Key question 1: How are work-related asthma cases diagnosed and how should they be diagnosed?

Key question 2: What are the risk factors (host and exposure) for a bad outcome?

Key question 3: What is the outcome of different management options in subjects who are already affected?

Key question 4: What are the benefits of medical screening and surveillance?

Key question 5: What is the impact of controlling work-related exposure to prevent asthma? 


\section{RESULTS}

Initially, our literature search provided 238 publications referring to key question 1, 164 to key question 2, 216 to key question 3, 137 to key question 4, and 72 to key question 5 (table sO1). After supplementary literature searches, we obtained 337, 181, 430, 182 and 199 publications, respectively, which were evaluated and served as the basis of the following statements and recommendations, as discussed in the Methods section.

\section{Key question 1: How are work-related asthma cases diagnosed and how should they be diagnosed?}

Ancillary questions: What is the sensitivity and specificity of diagnostic tests to identify work-related asthma? Is the workplace the cause of work-related asthma? What is the cause of work-related asthma?

\section{Statements}

1) In the clinical setting, questionnaires that identify symptoms of wheeze and/or shortness of breath which improve on days away from work or on holiday have a high sensitivity, but relatively low specificity for work-related asthma (**) [39-45].

2) Many workers with work-related asthma have increased nonspecific bronchial hyperresponsiveness (NSBHR) to methacholine or histamine, for example. However, a normal measurement cannot be used to exclude work-related asthma as there are many reports of normal bronchial responsiveness within $24 \mathrm{~h}$ of exposure in workers with confirmed occupational asthma $\left.{ }^{* * *}\right)[26,46,47]$.

3) The sensitivity and specificity of serial peak flow measurements is high in the diagnosis of work-related asthma $\left({ }^{* * *}\right)$ [48].

4) Pre- to post-shift changes in lung function cannot be recommended for the validation or exclusion work-related asthma $(* *)$ [49-51].

5) Changes in NSBHR at and away from work alone have only moderate sensitivity and specificity for diagnosis (**) [52-55].

6) Both skin-prick and specific IgE measurements are highly sensitive for detecting type 1 sensitisation and occupational asthma caused by most high molecular weight agents, but are not specific for diagnosing occupational asthma $(* * *)[26,43,56,57]$.

7) Both skin-prick and specific IgE measurement are sensitive for detecting type 1 sensitization and occupational asthma caused by acid anhydrides and some reactive dyes, but have a lower specificity for diagnosing occupational asthma $\left({ }^{* *}\right)$ [58-61].

8) Carefully controlled specific inhalative challenge (SIC) tests come closest to a gold standard test for many agents causing occupational asthma $\left(^{*}\right)[46]$.

9) A negative specific inhalative challenge test in a worker with otherwise good evidence of occupational asthma is not sufficient to exclude the diagnosis $\left({ }^{*}\right)[49,50,55,62-67]$.

10) Sputum eosinophils increasing by $>1 \%$ post SIC or workplace exposure may support a diagnosis of occupational asthma when the FEV1 has fallen $<20 \%\left(^{*}\right)$ [55].

11) The presence or absence of increased sputum eosinophils is not useful in selecting or excluding those who might have work-related asthma $\left({ }^{* *}\right)[55,68-72]$.
12) In the clinical setting, a finding of normal exhaled nitric oxide fraction cannot be used to exclude occupational asthma $(* *)[62,73-75]$.

\section{Comments}

The statements above are based, in the main, on the BOHRF guidelines [46], and are compatible with the AHRQ review [26] and the ACCP guidelines [3]. The evidence for serial measurements of peak expiratory flow (PEF) is taken from an evidence-based review [48] and is compatible with the AHRQ meta-analysis.

\section{Diagnosing work-related asthma}

Diagnostic tests can be divided into those that separate asthma from normality or other lung diseases, tests that identify the workplace as the cause of the respiratory symptoms, and tests that identify the agent causing the occupational asthma. The degree of proof required depends on the consequences of occupational asthma development for the individual worker. If the worker is likely to lose his job, occupational asthma should be confirmed physiologically and the specific agent causing the occupational asthma should be identified (for major causes, see table $\mathrm{sO} 4)[76,77]$. If it is possible to relocate the worker away from exposure without loss of income or prospects, a precise diagnosis is less important. The criteria for legal compensation vary between different administrations. Workers may have confirmed sensitisation-induced occupational asthma but may not fulfil the criteria for compensation in a particular country; management of this type of case can be particularly difficult.

Test that separate asthma from normality or other lung diseases Spirometry and tests for reversibility, increased diurnal variation in PEF, sputum eosinophilia and exhaled nitric oxide may all help confirm asthma, but may all be normal in individuals with occupational asthma confirmed with specific challenge tests. No measure of lung function or inflammatory marker is sufficiently sensitive to be used to exclude occupational asthma suggested by history (T.B. Aasen; personal communication) [26].

\section{Tests that identify the workplace as the cause of respiratory symptoms}

Respiratory symptoms that improve on days away from work or during holidays are the best screening method for possible occupational asthma; a positive response is not specific, as occupational asthma can only be confirmed in $\sim 50 \%$ of workers with wheeze that improves on days away from work. Measuring lung function in relation to work exposure is the best method of confirming occupational asthma. This can only be done when the patient is still exposed to the suspected cause of their symptoms, so it needs to be the first confirmatory test. Serial measurement of PEF on days at and away from work is the best validated method and is recommended in all guidelines [48]. Attention to detail is important. Minimum criteria are $\geqslant 3$ weeks of usual work exposure with measurements at least four times a day, or 8 work days and 3 rest days with 2-hourly measurements, with treatment being kept constant. Pre- and post-shift measurements of FEV1 and changes in NSBHR after a 2-week removal from work are less sensitive and less specific than serial PEF measurements. Workplace challenges are an alternative but are not standardised and lack external validation [78]. 
Tests that identify the agent causing work-related asthma Finding IgE specific to a well-characterised occupational allergen is insufficient for a diagnosis of occupational asthma alone, as sensitisation is more common than disease. However, the presence of specific IgE in a worker with confirmed occupational asthma from workplace measurements is sufficient to identify the specific cause. SIC is the best method of confirming the specific cause of occupational asthma when workplace measurements are not possible or specific IgE measurements are not available, as is the case for many low molecular weight agents. False-negative SIC do occur and were found in 29 out of 65 subjects with asthma or rhinitis and a good history of workplace deterioration, in a study using workplace challenges following negative SIC [67]. A supervised return to work with either a workplace challenge (for those with severe symptoms) or unsupervised PEF measurement on days at and away from work is helpful when occupational asthma is likely and SIC is negative.

\section{Recommendations}

The recommendations for key question 1 of these guidelines are presented in table 2 .

\section{Key question 2: What are the risk factors (host and exposure) for a bad outcome?}

Ancillary questions: Do the following eight specific factors present at the time of diagnosis have an influence on prognosis: lung function, duration of exposure, atopic status, smoking status, sex, age, agent, SIC pattern?

\section{Statements}

For references and comments, see MAESTRELLI et al. [79].

1) A substantial body of data indicates that lower lung volumes, higher NSBHR, or a stronger asthmatic response to SIC at diagnosis are risk factors for a bad occupational asthma outcome $\left.{ }^{* *}\right)$.

2) A substantial body of data suggests that longer symptomatic exposure relates to a worse occupational asthma outcome $\left.{ }^{* *}\right)$.
3) There is no relationship between atopy and the outcome of occupational asthma $\left({ }^{* * *}\right)$.

4) Smoking at the time of diagnosis is not related to the occupational asthma outcome. Although it is well established that smoking cessation is beneficial to the prognosis of asthma per se, smoking at the time for diagnosis does not seem to have a major impact on prognosis $\left.{ }^{* *}\right)$.

5) A limited body of data consider sex in the outcome of occupational asthma and the evidence is contradictory $\left({ }^{*}\right)$.

6) A sufficient body of data indicates that older age in patients is associated with poorer occupational asthma prognosis $\left({ }^{* *}\right)$.

7) A substantial body of data indicates an effect of the type of agents causing occupational asthma on outcome. High molecular weight (HMW) agents seem to cause longer duration of bronchial hyperresonsiveness compared with low molecular weight allergens $\left({ }^{* *}\right)$.

8) Due to the small number of papers with relevant findings, it is not clear whether the pattern of asthmatic response affects the prognosis of occupational asthma $\left({ }^{*}\right)$.

\section{Comments}

The outcome of occupational asthma after diagnosis is often poor. The identification of factors associated with a worse outcome may help in: planning appropriate management of the disease; determining its prognosis; and assessing the permanent impairment attributable to occupational exposure. The issue of factors associated with the outcome of occupational asthma has been considered in recent guidelines but not in a systematic manner. The ACCP [3], BOHRF [47] and AHRQ [26] agreed that longer symptomatic exposure relates to a worse outcome of occupational asthma. The BOHRF [47] concluded that better lung function at diagnosis relates to a better outcome of occupational asthma. The issue was not considered by the ACCP [3] and the AHRQ [26]. The ACCP [3] found that patients sensitised to HMW agents have more persistent NSBHR.

The present Task Force considered specific factors, in order to disentangle their respective influence on the prognosis of

TABLE 2 Recommendations for key question 1: How are work-related asthma cases diagnosed and how should they be diagnosed?

Recommendations
Strength of recommendation

Level of evidence

Occupational asthma should be confirmed by objective physiological tests and, in cases of allergic pathogenesis, by immunological tests

All adults with new, recurrent or deteriorating symptoms of asthma, chronic obstructive pulmonary disease or rhinitis should be asked about their job, materials with which they work and whether they improve when away from work

In cases of nonallergic (irritant) asthma, physicians should consider possible high exposure to irritants in the workplace as relevant pathogenetic factors

If, after full investigation, the diagnosis is still equivocal, follow-up evaluation is required by a specialist, including monitoring of spirometry, serial measurements of peak expiratory flow or spirometry, nonspecific bronchial hyperresponsiveness and allergological testing

Specific bronchial challenge testing is recommended when the diagnosis of occupational asthma is not clear beforehand, when the cause is new, or when it is necessary for the management of the individual worker. It should be performed in a centre with expertise in specific occupational challenge testing

We recommend a supervised workplace challenge if specific challenge testing is equivocal or not possible
Strong

High

Strong

High

Strong

Low

Strong

Low

Strong

Low

Strong

Low 
occupational asthma. The factors were: lung function at the time of diagnosis; duration of exposure; atopic status; smoking status at diagnosis; sex; age; type of causative agent; and the pattern of asthmatic reaction upon SIC. The statement on causal agents is in agreement with the conclusions of the ACCP [3]. It was not included in the conclusions of the BOHRF [47] and AHRQ [26]. Atopy, smoking, age, sex and the asthmatic pattern after SIC were not included in the conclusions of the ACCP [3], BOHRF [47] and AHRQ [26]. More detailed comments relating to individual statements have been provided by MAESTRELLI et al. [79].

\section{Recommendations}

The recommendations for key question 2 of these guidelines are presented in table 3 .

\section{Key question 3: What is the outcome of different management options in subjects who are already affected?} Ancillary questions: What are the consequences of persistent exposure to the causal agent? Is it possible to improve symptoms and lung function through pharmacological treatment in affected workers with persistent exposure? How effective is complete avoidance of exposure? How effective is the reduction of exposure through engineering controls or relocation of affected workers? How effective is the reduction of exposure through personal protective equipment?

\section{Statements}

For references, see VANDENPLAs et al. [80].

1) Persistent exposure to the causal agent is more likely to be associated with asthma and NSBHR persistence, as well as an accelerated decline in FEV1, compared with complete avoidance of exposure $\left.{ }^{* *}\right)$.

2) There is currently insufficient evidence that treatment with inhaled corticosteroids and long-acting $\beta_{2}$-agonists is able to prevent the long-term deterioration of asthma in subjects who remain exposed to the agent causing occupational asthma $\left(^{*}\right)$.

3) Occcupational asthma is associated with substantial longterm morbidity, as complete avoidance of exposure to the causal agent results in symptom recovery and resolution of NSBHR in less than one third of affected workers (***).

4) Reduction of exposure to the causal agent can lead to improvement or resolution of symptoms and NSBHR, although the limited evidence that is available indicates that this approach is less beneficial than cessation of exposure $\left.{ }^{* *}\right)$.
5) Personal respiratory equipment can result in an improvement, but not a complete suppression, of respiratory symptoms and airway obstruction in the short-term $\left(^{* *}\right)$.

\section{Comments}

What are the consequences of persistent exposure to the causal agent?

The systematic review conducted by BEACH et al. [26] concluded that workers with occupational asthma who remain exposed to the causal agent continue to experience stable or worsening asthma symptoms, and tend to show a decrease in FEV1 and an increase in NSBHR over time. This question was not specifically addressed in the clinical practice guidelines issued by the BOHRF [47] and the ACCP [3].

We identified nine studies that compared the effects of persistent exposure to causal agents with those resulting from complete avoidance in the same populations of workers with occupational asthma (see table sO3) [80-89]. Asthma symptoms persisted in almost all patients who remained exposed (93.0\% (95\% CI 86.3$96.6 \%)$ ), whereas $33.7 \%$ (95\% CI $23.6-45.6 \%$ ) of those who avoided exposure recovered from their asthma. The two studies that provided information on worsening of asthma reported that the condition deteriorated in 10 (59\%) out of 17 subjects who remained exposed, but in none of those who avoided exposure $[86,88]$. The few studies that compared the outcome of functional parameters reported that persistent exposure was associated with a decrease in FEV1 $[82,85,88]$ and an increase in NSBHR $[82,88]$, as compared with cessation of exposure, although the differences were significant in only one study [88].

Two retrospective cohort studies documented an accelerated decline in FEV1 in patients with occupational asthma. LIN et al. [90] studied patients with continued exposure to red cedar dust, in comparison with a control population of cedar sawmill workers. ANEES et al. [18] considered subjects with occupational asthma caused by various agents who had measurements taken before removal from the causal exposure.

Is it possible to improve symptoms and lung function through pharmacological treatment in affected workers with persistent exposure?

The effectiveness of anti-asthma medication in patients with persistent exposure has not been specifically addressed in previously published guidelines $[3,47]$ or in the AHRQ systematic review [26]. This question has been evaluated in one uncontrolled intervention study [91] and one retrospective cohort study [18]. MARABINI et al. [91] reported that, in comparison with

TABLE 3 Recommendations for key question 2: what are the risk factors (host and exposure) for a bad outcome?

Recommendations

Health practitioners should consider that early recognition and diagnosis of work-related asthma is recommended as a shorter symptomatic period after diagnosis is associated with a better outcome

Smoking habit and atopy should not be taken into account when assessing the prognosis for medical legal purposes

Further research is required in order to assess the effect on outcome of sex and the type of asthmatic response to specific bronchial challenge
Strength of recommendation

Level of evidence

$\begin{array}{lr}\text { Strong } & \text { High } \\ \text { Strong } & \text { Moderate } \\ \text { Strong } & \text { Moderate }\end{array}$


baseline values, there was no significant deterioration in asthma outcome in 10 subjects whose occupational asthma was caused by various agents and who were treated with beclomethasone (500 $\mu \mathrm{g}$ b.i.d.) and salmeterol (50 $\mu$ g b.i.d.) over a 3-yr period. In contrast, ANEES et al. [18] reported that the decline in FEV1 before removal from exposure to agents causing occupational asthma was not affected by the use of inhaled corticosteroids.

Recent case reports have suggested that treatment with omalizumab could substantially improve asthma control in subjects with flour-induced occupational asthma who remain exposed to the causal work environment [92, 93]; however, further investigations are required. There is evidence that specific immunotherapy with some HMW occupational agents has a beneficial effect; this approach is limited as standardised extracts are unavailable for most occupational allergens and there is potential for adverse reactions [94].

\section{How effective is complete avoidance of exposure?}

Two systematic reviews have examined the outcome of workers with occupational asthma after cessation of exposure in studies published up to 2004 [26, 95]. BEACH et al. [26] stated that most of the available studies documented an improvement in asthma symptoms and NSBHR, and an increase in mean FEV1, although few reported complete resolution of symptoms in the majority of the subjects. RACHIOTIS et al. [95] noted pooled rates of $32 \%(95 \%$ CI $26-38 \%)$ for symptomatic recovery and $73 \%$ (95\% CI 66-79\%) for the persistence of NSBHR. Analysis of eight studies published between March 2004 and December 2009 (see table sO2) [96-103] provided estimated rates similar to those reported by RACHIOTIS et al. [95]: $15.5 \%$ (95\% CI 8.3$27.1 \%$ ) for symptomatic recovery and $67.2 \%$ (95\% CI $45.7-$ $83.2 \%$ ) for the persistence of NSBHR.

Two retrospective cohort studies explored the long-term changes in functional indices after cessation of exposure [18, 104]. It was found that improvement in NSBHR can continue for years after cessation of exposure but the rate of improvement is steeper during the first $2.5 \mathrm{yrs}$ [104]. It was also noted that the decline in FEV1 after removal from exposure was similar to that observed in healthy adults [18]. Recent studies using induced sputum analysis documented that a lack of improvement in NSBHR after cessation of exposure was associated with persistent airway inflammation [105, 106], but inflammation [102] and airway remodelling [107] may be present in subjects who have recovered from symptoms and NSBHR.

Two randomised controlled trials have assessed the effects of systematic treatment with inhaled corticosteroids in addition to cessation of exposure [108, 109]. MAESTRELLI et al. [108] found that treatment with beclomethasone dipropionate $(1 \mathrm{mg}$ b.i.d. for 5 months) was associated with reduced NSBHR. MALO et al. [109] showed that beclomethasone dipropionate (1 mg daily) was associated with a significant, though minimal, improvement in symptoms, PEF values and quality of life (QoL) parameters.

Thus, there is insufficient evidence to support systematic treatment with high-dose inhaled corticosteroids in addition to cessation of the causal exposure; the pharmacological treatment of work-related asthma should focus on asthma control as is recommended for asthma in general [110, 111].
How effective is the reduction of exposure through engineering controls or relocation of affected workers?

Recent clinical practice guidelines have acknowledged that reduction of exposure may lead to improvement or resolution of asthma and could be considered an alternative to complete exposure avoidance, in order to minimise the socio-economic impact of occupational asthma when suppression of exposure is not feasible [3, 47]. The systematic review conducted by BEACH et al. [26] found that the majority of the studies on subjects with reduced exposure reported: some improvement in workers' symptoms; no clear pattern of change in medication use; an improvement in FEV1 over time in less than half of the studies; and insufficient data to draw conclusions about change in NSBHR. The authors concluded that there are insufficient data to draw conclusions about the effectiveness of reducing exposure.

We identified 10 studies comparing asthma outcome in subjects who had reduced exposure to the causal agent with those who completely avoided exposure [14, 82-84, 87, 103, 112-115]. Meta-analysis of pooled data showed that reduction of exposure was associated with a lower likelihood of improvement (OR 0.16 (95\% CI 0.03-0.91)) and recovery (OR 0.30 (95\% CI 0.11-0.84)) of asthma symptoms, and a higher risk of worsening of symptoms (OR 10.23 (95\% CI: 2.97-35.28)) and NSBHR (OR 5.65 (95\% CI 1.11-28.82)), as compared with complete avoidance of exposure (fig. 2) [35]. However, in the underlying studies, the exposure was not monitored objectively. Thus, it is not known to what extent the exposure was truly reduced and whether the derived exposure reduction can be regarded as substantial [35].

The few publications reporting on socio-economic outcomes suggested that reduction of exposure resulted in a lower rate of unemployment $[14,113]$; however, it remains uncertain whether reduced exposure is associated with a lower socio-economic impact than complete avoidance of exposure.

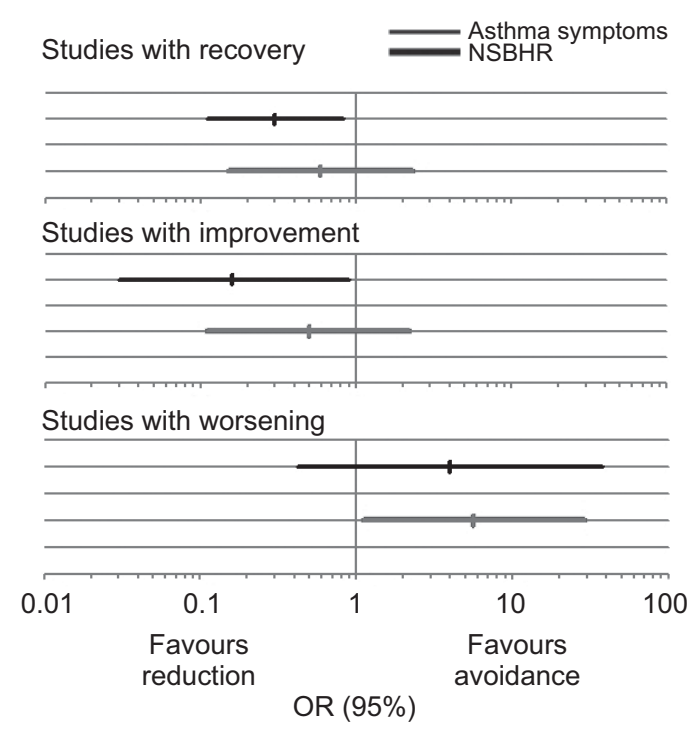

FIGURE 2. Forest plot of the meta-effect of cessation of exposure to the causal agent versus reduction of exposure (random effect model). 
How effective is the reduction of exposure through personal protective equipment?

The systematic review by BEACH et al. [26] referred to three studies that had examined the effectiveness of respiratory protective equipment (RPE) and had shown that these devices reduced the severity of acute respiratory symptoms but did not eliminate the symptoms [116-118]. The systematic review conducted by the BOHRF concluded that the use of RPE "may improve or prevent symptoms in some but not all workers" [47]; this approach was not addressed by the ACCP guidelines [3].

We identified four controlled studies that assessed the short-term effectiveness of RPEs in patients with occupational asthma (see [80] and table sO3), using laboratory inhalation challenges with organic farm allergens [119] and latex [118], or workplace exposure to laboratory animals [116], aluminum potroom atmosphere [120] and farming activity [117]. These studies showed that the use of RPE lead to a significant reduction in respiratory symptoms and changes in functional parameters during short-term exposures but failed to provide complete protection. One study documented that there was no protective effect in workers with a more severe asthma and in those who used RPE irregularly [117].

One retrospective study of workers with occupational asthma induced by red cedar dust who remained exposed to the causal agent, provided indirect evidence supporting a beneficial longterm effect of some RPEs, as the proportion of subjects who used a twin-cartridge respirator was higher among the group with stable asthma than among the group with a deterioration of asthma [121].

\section{General comment}

Determining the most effective treatment for occupational asthma would require comparison of the effect of different management options on clinical, physiological and socioeconomic outcomes. The evidence that can be derived from the available information is, however, largely limited by methodological weaknesses, with a high potential for selection bias. Most published data are from observational, non-randomised follow-up studies, and the rationale for the intervention decision (i.e. persistence, reduction or cessation of exposure) is largely unknown. In addition, asthma outcomes were measured and expressed in a highly heterogeneous manner. Finally, almost none of the studies relied on quantitative exposure assessments to document environmental intervention, such as persistence or reduction of exposure.

\section{Recommendations}

The recommendations for key question 3 of these guidelines are presented in table 4.

\section{Key question 4: What are the benefits of medical screening and surveillance?}

Ancillary questions: Is pre-placement screening for specific sensitisation to work-related allergens useful for the identification of those at higher risk of developing work-related asthma? Is pre-placement screening for a risk factor of occupational sensitisation or asthma, such as atopy, useful for the identification of those at higher risk of developing work-related asthma? Is pre-placement screening for NSBHR useful for the identification of those at higher risk of developing work-related asthma? Can genetic screening identify those at higher risk of developing work-related asthma? What is the impact of medical surveillance on the disease burden (prevalence) of work-related asthma? What are the useful components of medical surveillance for identification and intervention of work-related asthma?

\section{Statements}

For references and comments, see WILKEN et al. [122].

1) Workers (pre-)sensitised to allergens to which they will be exposed in their future work environment have an increased risk of developing occupational asthma or NSBHR soon after exposure $\left.{ }^{* * *}\right)$ [123-129].

2) Specific sensitisation can for this purpose be assessed by skin-prick test (SPT) with work-associated allergens and $\operatorname{IgE}$ serology $\left(^{* * *}\right)[123,129-132]$.

3) The positive predictive value of atopy screening results is not sufficiently predictive for future occupational sensitisation,
Patients, physicians and employers should be informed that persistence of exposure to the causal agent is likely to result in a deterioration of asthma symptoms and airway obstruction

Patients and their attending physicians should be aware that complete avoidance of exposure is associated with the highest probability of improvement, but may not lead to a complete recovery from asthma

Reduction of exposure to the causal agent can be considered an alternative to complete avoidance in order to minimise adverse socio-economic consequences; however, there is insufficient available evidence to recommend this option as a first-choice therapeutic strategy. This approach requires careful medical monitoring in order to ensure an early identification of asthma worsening

The use of respiratory protective equipment should not be regarded as a safe approach, especially in the long-term and in patients with severe asthma

Anti-asthma medications should not be regarded as a reasonable alternative to environmental interventions The pharmacological treatment of work-related asthma should be adapted to the level of asthma control, in accordance with the general recommendations for asthma
Strength of recommendation

Quality of evidence

$\begin{array}{lc}\text { Strong } & \text { Moderate } \\ \text { Strong } & \text { Moderate } \\ \text { Weak } & \text { Low } \\ & \\ \text { Strong } & \text { Low } \\ \text { Strong } & \text { Very low } \\ \text { Strong } & \text { Moderate }\end{array}$


work-related asthma or respiratory occupational allergy $(* * *)$ [124, 129, 133-136].

4) SPT with standardised high-quality allergen extracts is a suitable screening method for the identification of occupational sensitisation, as a work-related risk factor in workers exposed to high-molecular sensitisers such as laboratory animals, latex, enzymes or flour $\left.{ }^{* * *}\right)$ [123, 130-132].

5) A questionnaire separates individuals at low risk who do not need further care from those who need further clinical investigation and management $\left.{ }^{*}\right)$ [137-139].

6) The positive predictive value of NSBHR (observed preemployment as well as during employment) is not sufficiently reliable to be used as a predictive tool for occupational asthma (**) $[39,126,140-142]$.

7) Genetic markers measured at pre-employment are not helpful in predicting future occupational asthma. This is because they are far too weakly associated with the development of workrelated asthma, symptoms or other signs of work-related asthma $\left.{ }^{*}\right)$ [143-145].

8) A combination of different tests (questionnaires as well as physiological tests, immunological tests etc.) can improve the predictive value of individual screening methods (***) $[137,138,146]$.

9) Early detection of work-related respiratory symptoms, sensitisation and work-related asthma is possible using medical surveillance, which includes a questionnaire in combination with at least one of the following options: detection of specific sensitisation, NSBHR testing, SIC, diagnostic work up in a referral centre $\left.{ }^{* *}\right)[57,123,147-153]$.

10) Evaluations of surveillance programmes, consisting of medical surveillance (case finding), employers' feedback and exposure control measures, indicate that the incidence of workrelated asthma may decline following the introduction of a surveillance programme $(* *)$ [154-158].

11) Medical surveillance may reduce the occurrence of disability and socio-economic costs $\left(^{*}\right)$ [158].

12) Diagnostic models used in medical surveillance programmes should be carefully designed and clearly state where and how they should be used. Such diagnostic models have limited accuracy and need validation, calibration and, in many cases, an occupational agent tailored approach $\left(^{*}\right)[139,159]$.

\section{Comments}

Detailed comments relating to individual statements are provided by WILKEN et al. [122].

\section{Medical surveillance}

Medical surveillance is the analysis of health information to look for problems that may be occurring in the workplace and require targeted prevention. Surveillance can include both population- or group-based activities and individual activities. The individual-oriented activities are often referred to as worker screening and monitoring functions. However, medical surveillance is usually used in a broader context than screening because it is followed by intervention steps, which are aimed at improving the work environment in order to prevent further exacerbation or development of disease.

Both screening and medical surveillance are secondary preventive strategies. Their aim is: early detection; subsequent management of previously undiagnosed patients; increased opportunities for interventions to prevent progression of the disease emergence of symptoms and reduce duration of disease.

\section{Medical screening}

Medical screening is a method of detecting disease or body dysfunction before an individual would normally seek medical care. Screening tests are usually administered to individuals in a larger population who have not yet sought medical care, but who may be at a high risk of certain adverse health outcomes. In essence, it involves detection of individuals with an elevated probability of having the disorder of interest. In the occupational asthma field, the term screening is often used more loosely to refer to detection in individuals with existing disease (secondary or tertiary prevention) to avoid worsening. Related to screening is the activity to screen not for the presence of disease, but for the presence of risk factors of disease. This activity has been suggested for use in pre-employment or pre-placement evaluations. At a request of the World Health Organization (WHO), criteria for screening have been formulated to help decide whether screening in a particular situation should be recommended [160]. Among other criteria, the screening programme should: involve a major health problem; lead to improved prognosis; be acceptable for individuals undergoing the test; include clear criteria for referral; have undergone a cost assessment in comparison to the costs and benefits to the healthcare system; be a long-term service. The evidence potentially underpinning screening is explicitly considered in this document.

\section{Recommendations}

The recommendations for key question 4 of these guidelines are presented in table 5 .

\section{Key question 5: What is the impact of controlling work- related exposure to prevent asthma?}

Ancillary questions: Is elimination or reduction of workplace exposure to allergens and irritants effective for primary prevention of occupational sensitisation and asthma? How effective is reducing skin exposures to prevent occupational asthma? How effective is personal protective equipment (masks, respirators, gloves) in preventing occupational sensitisation and asthma?

\section{Statements}

For references and comments, see HEEDERIK et al. [161].

1) Complete elimination of the exposure is the most straightforward approach to reducing the burden of disease associated with occupational allergy and asthma $\left({ }^{* *}\right)$.

2) It seems extremely likely that exposure reduction will lead to a reduced disease burden of occupational asthma, as indicated by exposure-response relations. However, there is limited evidence available, provided by a few ecological and surveillance studies (uncertainty in the estimates of benefits, harms and burdens $(*))$. 
TABLE 5 Recommendations for key question 4: what are the benefits of medical screening and surveillance?

Questionnaire-based identification of all workers at risk of developing work-related asthma is Strong

A pre-placement screening for specific cross-reacting, work-associated sensitisation among potentially high molecular weight, allergen-exposed subjects is recommended in order to identify those at higher risk of work-related asthma

Detection of sensitisation either by specific immunoglobulin E or skin prick test should be included in surveillance (not only pre-placement) for identification of subjects at risk of work-related asthma with foreseeable regular exposure to high molecular weight agents (such as laboratory animals, bakery dust, enzymes or latex)

In atopic subjects and subjects with pre-existing asthma or sensitisation pre-employment, investigation should be performed in order to inform them about their increased risk of work-related asthma. Because of the low positive predictive value, exclusion of asymptomatic atopic subjects or sensitised subjects from exposure to potential occupational allergens or irritative agents cannot be recommended

Medical surveillance programmes should be performed in all workers with confirmed occupational rhinitis and/or nonspecific bronchial hyperresponsiveness. They should include periodic administration of a questionnaire, detection of sensitisation using standardised skin prick tests or serum-specific immunoglobulin $\mathrm{E}$ antibodies, early referral of symptomatic and/or sensitised subjects for specialised medical assessment and assessment of asthma. Surveillance programmes should be already performed during vocational training of individuals at risk

Identification of symptoms or sensitisation during surveillance should result in investigation to confirm or exclude occupational asthma, work-related asthma, rhinitis and chronic obstructive pulmonary disease

Risk stratification by diagnostic models can be used in medical surveillance to select exposed workers for further medical evaluation

A comprehensive medical surveillance programme as a secondary prevention measure should (in addition to early detection of sensitisation, allergic symptoms, and occupational asthma) comprise of exposure

assessment and intervention targeted both at workers and exposure

$\begin{array}{lr}\text { Strong } & \text { Moderate } \\ \text { Strong } & \text { Moderate } \\ \text { Weak } & \text { Moderate } \\ \text { Strong } & \text { Moderate } \\ & \\ \text { Strong } & \text { High } \\ \text { Strong } & \text { Moderate } \\ \text { Strong } & \text { Moderate }\end{array}$

3) Substitution of natural rubber latex (NRL) greatly reduces NRL sensitisation and the occurrence of NRL-related asthma. Strong evidence has been provided by scientific studies $\left({ }^{* * *}\right)$.

4) Skin exposure regularly occurs and there is limited evidence that it contributes to the onset of occupational sensitisation and asthma. Limited evidence has been provided mainly by case reports and animal experimental studies (uncertainty in the estimates of benefits, harms and burdens $\left({ }^{*}\right)$ ).

5) Use of RPE can contribute to primary prevention in occupational asthma. Limited evidence has been provided by a few studies (uncertainty in the estimates of benefits, harms, and burdens $\left(^{*}\right)$ ).

\section{Comments}

Similar statements and recommendations for primary prevention appear in the documents published by the BOHRF [47] and the ACCP [3]. Both documents recommended control of exposure levels as a means of implementing primary prevention of occupational asthma, similar to the current recommendations. While the other documents also call for the use of respirators to control exposures, the current recommendation goes further, placing respirator use in the hierarchy of other control options. The recommendation, regarding stopping the use of allergenrich NRL gloves, is not found in the other documents. The ACCP document addresses the possible contribution of skin exposure to the onset of sensitisation and occupational asthma in a discussion of exposure and exposure assessment. Although there is limited evidence, the current document recommends minimising skin exposure to asthma-inducing agents.

In the hierarchy of controls for occupational health hazards, eliminating or minimising exposure at the source or in the environment is considered more effective than providing personal protective equipment for the worker [162]. The success of respiratory personal protection requires an ongoing commitment by employers and employees to a programme that includes selection, cleaning, maintenance and storage of equipment, as well as training, fit testing and medical monitoring of users. Respirators are best used as an interim measure whilst efforts to control exposures at the source or in the environment are being implemented, or when controls at these other levels are not possible. Perhaps as respirators are not considered an optimal way of controlling exposures, they have often been used in conjunction with other control activities at the source and/or environmental level. Such comprehensive programmes have been implemented for workers exposed to laboratory animals [163-165], detergent enzymes [166], dusts and fumes in aluminum production [167], diisocyanates [112, 168] and disinfectants [169]. While many of these programmes have reported success at prevention, it is not possible to determine the contribution made by respirators alone.

A review of the medical literature revealed very few articles that specifically address the effectiveness of respiratory protection for preventing the onset of asthma. Prior studies have illustrated 
a positive relationship between work-related asthma and the level of exposure to wheat allergen [170] and isocyanates [81]. A reduction in exposure should be beneficial, and two recent studies report how respirators can reduce exposure to these two asthma agents. In one study, investigators used intranasal air samplers to determine wheat allergen levels both inside and outside a P2 particle filter face mask [171]. Exposures levels were reduced by $93-96 \%$ using the facemasks, and the investigators concluded that these respirators might help to prevent bakers' asthma. Another study of 22 spray painters in automobile body shops evaluated the effectiveness of respiratory protection against isocyanate exposure [172]. The investigators conducted workplace measurements of the total isocyanate group (NCO) both inside and outside negative pressure, airpurifying half-face respirators with organic vapor cartridges and paint pre-filters. The authors concluded that these respirators provided reasonably effective protection if the workers were trained and fit tested. Despite the encouraging findings from these two studies, neither directly tested whether the reduced exposure levels were associated with a decline in asthma onset.

A more direct investigation of the value of respiratory protection for primary prevention was conducted amongst workers who were manufacturing an epoxy resin that required hexahydrophthalic anhydride [173]. Study participants were offered a choice of three different respirators: a disposable dust and mist respirator; a half-face organic vapor respirator; or a full-face organic vapor respirator. The highest annual incidence for asthma over the 7 yrs of follow-up was $2 \%$, compared with $\sim 10 \%$ observed in employees before the introduction of respirators. There was no statistically significant difference between respirators, but none of the workers who wore the fullface respirators developed occupational asthma, even those who worked in high-exposure jobs. More detailed comments to individual statements are provided by HEEDERIK et al. [161].

\section{Recommendations}

The recommendations for key question 5 of these guidelines are presented in table 6 .

\section{DISCUSSION}

The objective of the Task Force was to systematically gather existing evidence on management options for work-related asthma and the effectiveness of those options. The relevant topics included diagnostic aspects, identification of risk factors, screening and surveillance, as well as preventive measures in dangerous worksites and the optimal treatment for affected subjects. Five key questions and a variety of ancillary questions were formulated and addressed.

A general and major issue in relation to occupational asthma research is that most of the evidence is observational; few intervention studies, with randomised or cross-over designs, have been undertaken and published. Observational studies generally receive lower scores than experimental study designs. The reason these lower scores are not given is not because the observational studies were poorly conducted. On the contrary, most were of sufficient quality. But experimental studies are valued more highly because of the higher level of control. Few interventions are undertaken in this field, mainly because of numerous practical constraints, like permission and cooperation of employers and employees, and potentially ethical constrains when interventions involve occupational asthma patients.

The Global Initiative for Asthma (GINA) has revised its guidelines and changed its focus from asthma severity to asthma control, with an emphasis on carefully titrating drug doses, according to the level of control [110, 174]. This new understanding is also relevant for management of work-related asthma. However, in terms of work-related asthma, the benefits from avoiding exposure far exceed those of drug treatment.

In clinical decision-making for work-related asthma, physicians must be able to: identify whether a patient is adequately controlled; understand how increments of control can be achieved by adjusting exposure levels and/or the therapeutic regimen; and evaluate the resulting improvements or lack thereof.

Recent papers evaluated and compared existing instruments for measuring asthma control [110,111]. Five validated instruments that were designed to measure asthma control demonstrated validity and responsiveness, with some measure of reliability, and all had evidence to support their use in clinical decisionmaking. The individual GINA characteristics of asthma control to be checked were: daytime symptoms; limitations of activities; noctural symptoms/awakening; need for reliever/rescue treatment; lung function (PEF or FEV1); and exacerbations. Other characteristics that were not included in GINA but were considered by some investigators were: airway inflammation; patients' perception of asthma control; overall asthma severity; and specific asthma symptoms (i.e. shortness of breath, wheezing or cough, or chest pain). For the measurement of workrelated asthma control, the following characteristics were added:

\section{TABLE 6 Recommendations for key question 5: what is the impact of controlling work-related exposure to prevent asthma?}

Recommendations
Strength of recommendation

Level of evidence

Exposure elimination is the strongest preventive approach to reducing the disease burden of work-related asthma and is the preferred primary-prevention approach

If elimination is not possible, reduction is the second best option for primary prevention of work-related asthma based on exposure-response relationships

There is limited evidence of the effectiveness of respirators in preventing occupational asthma, and other options that are higher in the hierarchy of controls for occupational exposures, notably eliminating or minimising exposures at the source or in the environment, should be used preferentially.

Do not use powdered allergen-rich natural rubber latex gloves

Minimise skin exposure to asthma-inducing agents

$\begin{array}{lc}\text { Strong } & \text { High } \\ \text { Strong } & \text { Moderate } \\ \text { Strong } & \text { Moderate } \\ & \\ \text { Strong } & \text { High } \\ \text { Strong } & \text { Low }\end{array}$

VOLUME 39 NUMBER 3 
work-related symptoms and work-related lung function impairment (PEF or FEV1). To maintain clinical control, which is challenging and the most important aim, the following additional factors should be taken into account: intensity and variability of exposure to causative occupational agent(s); individual exposure-response relations; the underlying pathogenetic mechanisms (i.e. allergic or irritative effects at high, medium or low concentrations); impairment of lung function and degree of NSBHR; and realistic secondary and tertiary preventive measures in the particular case.

Evaluating the outcome of work-related asthma is not only based on clinical aspects but includes physiological as well as social variables. The relevant literature was recently summarised in systematic reviews [95, 175, 176]. RACHIOTIS et al. [95] summarised as follows: "one third of patients with occupational asthma will recover fully from their disease allowing avoidance of exposure to the initiating agent. This proportion seems not to be related to the duration of avoidance. In most cases, nonspecific bronchial responsiveness detected at diagnosis persists [...] There was evidence that symptomatic outcomes worsened with increasing age and with duration of symptomatic exposure, although the latter was not significant." For results of the literature search on the clinical outcome of work-related asthma, see online supplementary text sO5.

In conclusion, we suggest using existing recommendations from GINA to optimise the assessment of the effect of interventions on clinical and physiological indices and to control the consequences on employment and income. Work-related symptoms, lung function deterioration and sensitisation are major parameters for decision-making in work-related asthma management. The combination of a questionnaire, with results of SPT and/or IgE tests, increases the predictive value significantly [138]. Screening as well as surveillance results and NSBHR were found to be informative prognostic parameters in high-risk workers. Since the level of exposure to allergenic or irritative airborne agents is the dominant risk factor for work-related asthma, exposure avoidance or at least reduction as primary preventive measures are the most effective approaches. This is obviously also true for occupational COPD [18-20]. There is less evidence for the effectiveness of secondary prevention, in which sensitisation or early symptoms are identified during health surveillance programmes, with the aim of a substantial reduction in and, if possible, avoidance of further causative exposures. Tertiary prevention of occupational airway diseases involves a therapeutic and general asthma or COPD management plan, and may include a change of workplace or even job for individuals who continue to have work-related symptoms, despite efforts to control exposures and optimise management. Pharmacological treatment and respirators are of limited effect. The limited amount of data about the relationship of work-related asthma with sex, age, smoking and type of agent does not allow recommendations to be made about these factors.

The aforementioned management options refer to new-onset occupational asthma as well as work-aggravated asthma. The latter can be differentiated from occupational asthma by the temporally work-associated worsening of pre-existing or concurrent work-independent asthma (see Chapter introduction of the publication). Although there are only a few studies on the management of work-aggravated asthma [3, 177], there is general agreement that reduction of causative exposures and intensified surveillance and treatment are urgent measures for management. If this approach is not successful, a change in jobs should be considered [178].

Increased suspicion of an occupational cause in all cases of asthma and COPD by all involved is required. On the basis of the key and ancillary questions and evidence-based statements, our recommendations for the effective prevention and management of work-related asthma are: 1) avoidance of causative exposures or, if that is not possible, exposure reduction; 2) screening and monitoring (surveillance) of endangered workers (those with high-risk work sites or with individual susceptibility); comprehensive assessment of disease in suspected cases (diagnostics); pharmacological treatment of subjects with obstructive ventilation patterns, NSBHR or work-related asthma symptoms.

Furthermore, there is a need for patient health education, in an effort to improve the individual's ability to cope with unplanned harmful exposures, exacerbation episodes, avoidance of risk factors and smoking cessation. We also recommend providing detailed information to employees, employers and medical personnel, which should lead to increased awareness and earlier detection of work-related asthma and occupational COPD. We recommend notification to accessible registers and systematic surveys that may detect increased occurrence of asthma and COPD in populations. Since many epidemiological studies are hypothesis-generating, this may lead to more focused investigations, which in turn may form a basis for prevention.

\section{Limitations of these guidelines}

There is the possibility of publication or article-retrieval bias; some studies may not have been found by use of the MeSH terms and keywords used to search for articles. Another limitation was that not all studies presented data in an evaluable form; the studies included in the sections on management displayed considerable heterogeneity. Also, in the section on management, the methodological quality of the studies was relatively weak, and randomised controlled trials were not available and would be unethical. The interventions were generally heterogeneous and allocation was not randomised; the outcome assessments were often incomparable and tended to focus on physiological test results.

\section{Future research aspects}

Given the limited evidence available, additional research is required to demonstrate the effectiveness of primary preventive measures on: allergen exposure; and the occurrence of allergy and asthma for most allergens. In general, studies that make use of strong analytical designs, such as randomised controlled trials and controlled intervention studies, have the potential for allergen exposure. Observational studies, which focus on disease occurrence in relation to exposure, have further limitations. Exposure studies focusing on evaluation of allergen exposure and exposure interventions are strongly encouraged. Further evidence is required for all types of preventive actions, including improved ventilation, education of workers, changes in work organisation, and use of personal protective equipment.

There is a clear need to further explore the role of skin exposure in relation to development of sensitisation and disease occurrence. 
Given earlier information, it is important to evaluate the independent and additional predictive value of diagnostic tests. Prediction research provides an appropriate solution by using a multivariate approach in design and analysis that accounts for mutual dependence between different test results. The information from these tests can then be translated into a predicted probability of the chosen outcome. Prediction models applied in occupational health practice may therefore enable an occupational physician to deal with uncertainties in considering workers at risk of having occupational diseases.

Research is needed to assess the prognostic value of sex, type of asthmatic response to specific bronchial challenge, and other determinants at diagnosis. Furthermore, most research on risk factors for a bad outcome is performed on a limited number of exposures, i.e. isocyanates and western red cedar. So it is crucial to include other exposures in the research field as well.

Although its role in disease management is not disputed, there are important questions that are still awaiting answers: when and how to set up medical surveillance; and which tests, test frequency and outcome parameters should be used in different occupational groups. As direct evidence for the benefit of medical surveillance is limited, there is a need for prospective studies using clearly defined instruments and outcomes.

Large-scale, standardised studies on the prognosis of occupational asthma and its determinants after environmental interventions are required in order to provide evidence-based recommendations to affected workers, employers and policy makers. Prospective studies of the prognosis of occupational asthma should use the outcomes that have been validated for asthma in general.

\section{SUPPORT STATEMENT}

The work of the Task Force on the Management of Work-related Asthma was funded by the European Respiratory Society. The findings and conclusions in this report are those of the authors and do not necessarily represent the views of the National Institute for Occupational Safety and Health.

\section{STATEMENT OF INTEREST}

Statements of interest for V. Schlünssen and P.S. Burge can be found at www.erj.ersjournals.com/site/misc/statements.xhtml

\section{ACKNOWLEDGEMENTS}

The author affiliation details are as follows. X. Baur (Task Force Chair): Institute for Occupational and Maritime Medicine, University Medical Center Hamburg-Eppendorf, Hamburg, Germany. T. Sigsgaard (Task Force Co-Chair): Aarhus University, Dept of Environmental and Occupational Medicine, School of Public Health, Åarhus, Denmark. T.B. Aasen: Haukeland University Hospital, Bergen, Norway. P.S. Burge: Heart of England NHS Foundation Trust, Dept of Respiratory Medicine, Birmingham, UK. D. Heederik: Environmental Epidemiology Division, Institute for Risk Assessment Sciences (IRAS), University of Utrecht, Utrecht, the Netherlands. P. Henneberger: National Institute for Occupational Safety and Health, Centers for Disease Control and Prevention, Morgantown, WV, USA. P. Maestrelli: Dept of Environmental Medicine and Public Health, University of Padova, Padova, Italy. J. Rooyackers: Netherlands Expertise Center for Occupational Respiratory Disorders - NECORD IRAS NKAL, Utrecht, the Netherlands. V. Schlünssen: Aarhus University, Aarhus, Denmark. O. Vandenplas: Dept of Chest Medicine, Mont-Godinne Hospital, Université Catholique de Louvain, Yvoir, Belgium. D. Wilken: Institute for Occupational and
Maritime Medicine, University Medical Center Hamburg-Eppendorf, Hamburg, Germany.

Additional members of the ERS Task Force on the Management of Work-related Asthma were as follows. H. Dressel: Städt. Klinikum München GmbH Klinikum Neuperlach Zentrum für Akutgeriatrie und Frührehabilitation, Munich, Germany. C.A. Redlich: Yale Occupational/ Environ mental, New Haven, CT, USA.

\section{REFERENCES}

1 Bernstein IL, Chan-Yeung M, Malo JL, et al. Asthma in the workplace and related conditions. 3rd Edn. New York, Taylor \& Francis, 2006.

2 Baur X, Aasen T, Burge S, et al. The management of work-related asthma guidelines: a broader perspective. Eur Respir Rev 2012 (in press).

3 Tarlo SM, Balmes J, Balkissoon R, et al. Diagnosis and management of work-related asthma: American College of Chest Physicians Consensus Statement. Chest 2008; 134: 1S-41S.

4 Davison AG, Fayers PM, Taylor AJ, et al. Cadmium fume inhalation and emphysema, 1988; 1: 663-667.

5 Postma DS, Boezen HM. Rationale for the Dutch hypothesis. Allergy and airway hyperresponsiveness as genetic factors and their interaction with environment in the development of asthma and COPD. Chest 2004; 126: 96S-104S; discussion 159S-161S.

6 Hargreave FE, Parameswaran K. Asthma, COPD and bronchitis are just components of airway disease. Eur Respir J 2006; 28: 264-267.

7 Meldrum M, Rawbone R, Curran AD, et al. The role of occupation in the development of chronic obstructive pulmonary disease (COPD). Occup Environ Med 2005; 62: 212-214.

8 Hnizdo E, Sullivan PA, Bang KM, et al. Association between chronic obstructive pulmonary disease and employment by industry and occupation in the US population: a study of data from the Third National Health and Nutrition Examination Survey. Am J Epidemiol 2002; 156: 738-746.

9 Christiani DC. Occupation and COPD. Occup Environ Med 2005; 62: 215.

10 Bergdahl IA, Toren K, Eriksson K, et al. Increased mortality in COPD among construction workers exposed to inorganic dust. Eur Respir J 2004; 23: 402-406.

11 Balmes JR, Nowak D. COPD caused by occupational exposure. In: Donner CF, Carone M, eds. COPD. Oxford, Clinical publishing, 2007; pp. 85-95.

12 American Thoracic Society. Standards for the diagnosis and care of patients with chronic obstructive pulmonary disease. Am J Respir Crit Care Med 1995; 152: 77-121.

13 Davison AG, Fayers PM, Taylor AJ, et al. Cadmium fume inhalation and emphysema. Lancet 1988; 1: 663-667.

14 Vandenplas O, Jamart J, Delwiche JP, et al. Occupational asthma caused by natural rubber latex: outcome according to cessation or reduction of exposure. J Allergy Clin Immunol 2002; 109: 125-130.

15 Vandenplas O, Malo JL, Pauli G. Hyperreactivite bronchique non allergenique et agents professionnels [Non-allergenic bronchial hyperreactivity and occupational agents]. Rev Mal Respir 1994; 11: 189-199.

16 Bourdin A, Serre I, Flamme H, et al. Can endobronchial biopsy analysis be recommended to discriminate between asthma and COPD in routine practice? Thorax 2004; 59: 488-493.

17 Hargreave FE, Nair P. The definition and diagnosis of asthma. Clin Exp Allergy 2009; 39: 1652-1658.

18 Anees W, Moore VC, Burge PS. FEV1 decline in occupational asthma. Thorax 2006; 61: 751-755.

19 Blanc PD, Torén K. Occupation in chronic obstructive pulmonary disease and chronic bronchitis: an update. Int J Tuberc Lung Dis 2007; 11: 251-257. 
20 Salvi SS, Barnes PJ. Chronic obstructive pulmonary disease in non-smokers. Lancet 2009; 374: 733-743.

21 Behrendt CE. Mild and moderate-to-severe COPD in nonsmokers: distinct demographic profiles. Chest 2005; 128: 1239-1244.

22 Lamprecht B, Schirnhofer L, Kaiser B, et al. Farming and the prevalence of non-reversible airways obstruction: results from a population-based study. Am J Ind Med 2007; 50: 421-426.

23 Ulvestad B, Bakke B, Eduard W, et al. Cumulative exposure to dust causes accelerated decline in lung function in tunnel workers. Occup Environ Med 2001; 58: 663-669.

24 Weinmann S, Vollmer WM, Breen V, et al. COPD and occupational exposures: a case-control study. J Occup Environ Med 2008; 50: 561-569.

25 Newman Taylor AJ, Cullinan $\mathrm{P}$, et al. BOHRF guidelines for occupational asthma. Thorax 2005; 60: 364-366.

26 Beach J, Rowe BH, Blitz S, et al. Diagnosis and management of work-related asthma. Evidence report/technology assessment no 129. US Department of Health and Human Services, Agency for Healthcare Research and Quality. www.ahrq.gov/downloads/ pub/evidence/pdf/asthmawork/asthwork.pdf Date last updated: November 2005. Date last accessed January 16, 2012.

27 Mannino DM. How much asthma is occupationally related? Occup Med 2000; 15: 359-368.

28 Balmes J, Becklake M, Blanc P, et al. American Thoracic Society Statement: Occupational contribution to the burden of airway disease. Am J Respir Crit Care Med 2003; 167: 787-797.

29 Kogevinas M, Zock JP, Jarvis D, et al. Exposure to substances in the workplace and new-onset asthma: an international prospective population-based study (ECRHS-II). Lancet 2007; 370: 336-341.

30 Latza U, Baur X. Occupational obstructive airway diseases in Germany: frequency and causes in an international comparison. Am J Ind Med 2005; 48: 144-152.

31 Boyd R, Cowie H, Hurley F, et al. The true cost of occupational asthma in Great Britain. Research Report 474. Suffolk, Health \& Safety Executive (HSE), 2006.

32 Harbour R, Miller J. A new system for grading recommendations in evidence based guidelines. BMJ 2001; 323: 334-336.

33 Vlaanderen J, Vermeulen R, Heederik D, et al. Guidelines to evaluate human observational studies for quantitative risk assessment. Environ Health Perspect 2008; 116: 1700-1705.

34 Lenters V, Vermeulen R, Dogger S, et al. A meta-analysis of asbestos and lung cancer: is better quality exposure assessment associated with steeper slopes of the exposure-response relationships? Environ Health Perspect 2011; 119: 1547-1555.

35 Vandenplas O, Dressel H, Wilken D, et al. Management of occupational asthma: cessation or reduction of exposure? A systematic review of available evidence. Eur Respir J 2011; 38: 804-811.

36 The Royal College of General Practitioners. The development and implementation of clinical guidelines. Report of the Clinical Guidelines Working Group. London, RCGP, 1995.

37 Atkins D, Best D, Briss PA, et al. Grading quality of evidence and strength of recommendations. BMJ 2004; 328: 1490.

38 Schunemann HJ, Jaeschke R, Cook DJ, et al. An official ATS statement: grading the quality of evidence and strength of recommendations in ATS guidelines and recommendations. Am J Respir Crit Care Med 2006; 174: 605-614.

39 Baur X, Huber H, Degens PO, et al. Relation between occupational asthma case history, bronchial methacholine challenge, and specific challenge test in patients with suspected occupational asthma. Am J Ind Med 1998; 33: 114-122.

40 Cote J, Kennedy S, Chan-Yeung M. Quantitative versus qualitative analysis of peak expiratory flow in occupational asthma. Thorax 1993; 48: 48-51.

41 Malo JL, Ghezzo H, L'Archeveque J, et al. Is the clinical history a satisfactory means of diagnosing occupational asthma? Am Rev Respir Dis 1991; 143: 528-532.
42 Merget R, Schultze-Werninghaus G, Muthorst T, et al. Asthma due to the complex salts of platinum - a cross-sectional survey of workers in a platinum refinery. Clin Allergy 1988; 18: 569-580.

43 Vandenplas O, Delwiche JP, Evrard G, et al. Prevalence of occupational asthma due to latex among hospital personnel. Am J Respir Crit Care Med 1995; 151: 54-60.

44 Vandenplas O, Binard-Van Cangh F, Brumagne A, et al. Occupational asthma in symptomatic workers exposed to natural rubber latex: evaluation of diagnostic procedures. J Allerg Clin Immunol 2001; 107: 542-547.

45 Vandenplas $\mathrm{O}$, Ghezzo $\mathrm{H}$, Munoz $\mathrm{X}$, et al. What are the questionnaire items most useful in identifying subjects with occupational asthma? Eur Respir J 2005; 26: 1056-1063.

46 Nicholson PJ, Cullinan P, Burge PS, et al. eds. Occupational Asthma: Prevention, Identification and Management: Systematic Review \& Recommendations. London, British Occupational Health Research Foundation, 2010.

47 Nicholson PJ, Cullinan P, Taylor AJ, et al. Evidence based guidelines for the prevention, identification, and management of occupational asthma. Occup Environ Med 2005; 62: 290-299.

48 Moore VC, Jaakkola M, Burge P. A systematic review of serial peak expiratory flow measurements in the diagnosis of occupational asthma. Ann Respir Med 2010; 1: 31-44.

49 Burge PS, O'Brien IM, Harries MG. Peak flow rate records in the diagnosis of occupational asthma due to colophony. Thorax 1979; 34: 308-316.

50 Burge PS, O'Brien IM, Harries MG. Peak flow rate records in the diagnosis of occupational asthma due to isocyanates. Thorax 1979; 34: 317-323.

51 Park D, Moore VC, Burge CB, et al. Serial PEF measurement is superior to cross-shift change in diagnosing occupational asthma. Eur Respir J 2009; 34: 574-578.

52 Cote J, Kennedy S, Chan-Yeung M. Sensitivity and specificity of PC20 and peak expiratory flow rate in cedar asthma. J Allerg Clin Immunol 1990; 85: 592-598.

53 Perrin B, Lagier F, L'Archeveque J, et al. Occupational asthma: validity of monitoring of peak expiratory flow rates and non-allergic bronchial responsiveness as compared to specific inhalation challenge. Eur Respir J 1992; 5: 40-48.

54 Tarlo SM, Broder I. Outcome of assessments for occupational asthma. Chest 1991; 100: 329-335.

55 Girard F, Chaboillez S, Cartier A, et al. An effective strategy for diagnosing occupational asthma: use of induced sputum. Am J Respir Crit Care Med 2004; 170: 845-850.

56 Baur X, Czuppon A. Diagnostic validation of specific IgE antibody concentrations, skin prick testing, and challenge tests in chemical workers with symptoms of sensitivity to different anhydrides. J Allerg Clin Immunol 1995; 96: 489-494.

57 Platts-Mills TA, Longbottom J, Edwards J, et al. Occupational asthma and rhinitis related to laboratory rats: serum $\operatorname{IgG}$ and $\operatorname{IgE}$ antibodies to the rat urinary allergen. J Allerg Clin Immunol 1987; 79: 505-515.

58 Grammer L, Shaughnessy M, Kenamore B. Utility of antibody in identifying individuals who have or will develop anhydrideinduced respiratory disease. Chest 1998; 114: 1199-1202.

59 Howe W, Venables KM, Topping MD, et al. Tetrachlorophthalic anhydride asthma: evidence for specific IgE antibody. J Allerg Clin Immunol 1983; 71: 5-11.

60 Park HS, Kim YJ, Lee MK, et al. Occupational asthma and IgE antibodies to reactive dyes. Yonsei Med J 1989; 30: 298-304.

61 Park JW, Kim CW, Kim KS, et al. Role of skin prick test and serological measurement of specific $\operatorname{IgE}$ in the diagnosis of occupational asthma resulting from exposure to vinyl sulphone reactive dyes. Occup Environ Med 2001; 58: 411-416.

62 Baur X, Barbinova L. Increase of exhaled nitric oxide (eNO) after methylene diphenyl diisocyanate (MDI) exposure in isocyanate 
workers with bronchial hyperresponsiveness. Allergology Int 2005; 54: 151-158.

63 Cartier A, Grammer L, Malo JL, et al. Specific serum antibodies against isocyanates: association with occupational asthma. J Allerg Clin Immunol 1989; 84: 507-514.

64 Lin FJ, Chen H, Chan-Yeung M. New method for an occupational dust challenge test. Occup Environ Med 1995; 52: 54-56.

65 Moscato G, Dellabianca A, Vinci G, et al. Toluene diisocyanateinduced asthma: clinical findings and bronchial responsiveness studies in 113 exposed subjects with work-related respiratory symptoms. J Occup Med 1991; 33: 720-725.

66 Munoz X, Cruz MJ, Orriols R, et al. Validation of specific inhalation challenge for the diagnosis of occupational asthma due to persulphate salts. Occup Environ Med 2004; 61: 861-866.

67 Rioux JP, Malo JL, L'Archeveque J, et al. Workplace-specific challenges as a contribution to the diagnosis of occupational asthma. Eur Respir J 2008; 32: 997-1003.

68 Alvarez MJ, Estrada JL, Gozalo F, et al. Oilseed rape flour: another allergen causing occupational asthma among farmers. Allergy 2001; 56: 185-188.

69 Krakowiak A, Krawczyk-Adamus P, Dudek W, et al. Changes in cellular and biochemical profiles of induced sputum after allergen-induced asthmatic response: method for studying occupational allergic airway inflammation. Int J Occup Med Environ Health 2005; 18: 27-33.

70 Lemiere C, Chaboillez S, Malo JL, et al. Changes in sputum cell counts after exposure to occupational agents: what do they mean? J Allerg Clin Immunol 2001; 107: 1063-1068.

71 Maestrelli P, Calcagni PG, Saetta M, et al. Sputum eosinophilia after asthmatic responses induced by isocyanates in sensitized subjects. Clin Exp Allergy 1994; 24: 29-34.

72 Obata H, Dittrick M, Chan H, et al. Sputum eosinophils and exhaled nitric oxide during late asthmatic reaction in patients with western red cedar asthma. Eur Respir J 1999; 13: 489-495.

73 Baur X, Barbinova L. Latex allergen exposure increases exhaled nitric oxide in symptomatic healthcare workers. Eur Respir J 2005; 25: 309-316.

74 Piipari R, Piirila P, Keskinen H, et al. Exhaled nitric oxide in specific challenge tests to assess occupational asthma. Eur Respir J 2002; 20: 1532-1537.

75 Barbinova L, Baur X. Increase in exhaled nitric oxide (eNO) after work-related isocyanate exposure. Int Arch Occup Environ Health 2006; 79: 387-395.

76 Malo JL, Chan-Yeung M. Agents causing occupational asthma with key references. In: Bernstein IL, Chan-Yeung M, Malo JL, et al., eds. Asthma in the Workplace. 3rd Edn. New York, Taylor \& Francis Group, 2006.

77 Baur X. Airborne allergens and irritants in the workplace. In: Kay $\mathrm{AB}$, Kaplan AP, Bousquet J, et al, eds. Allergy and Allergic Diseases. Oxford, Blackwell Publishing, 2008; pp. 1017-1122.

78 Stenton SC, Avery AJ, Walters EH, et al. Statistical approaches to the identification of late asthmatic reactions. Eur Respir J 1994; 7 : 806-812.

79 Maestrelli P, Schlünssen V, Mason P, et al. Contribution of host factors and workplace exposure to the outcome of occupational asthma. Eur Respir Rev 2012 (in press).

80 Vandenplas O, Dressel H, Nowak D, et al. What is the optimal management option for occupational asthma? Eur Respir Rev 2012 (in press).

81 Tarlo SM, Banks D, Liss G, et al. Outcome determinants for isocyanate induced occupational asthma among compensation claimants. Occup Environ Med 1997; 54: 756-761.

82 Chan-Yeung M, MacLean L, Paggiaro PL. Follow-up study of 232 patients with occupational asthma caused by western red cedar (Thuja plicata). J Allergy Clin Immunol 1987; 79: 792-796.
83 Rosenberg N, Garnier R, Rousselin X, et al. Clinical and socioprofessional fate of isocyanate-induced asthma. Clin Allergy 1987; 17: 55-61.

84 Moscato G, Bertoletti R, Biscaldi G, et al. Occupational asthma: fate and management after the diagnosis. G Ital Med Lav 1993; 15: 27-31.

85 Gannon PF, Weir DC, Robertson AS, et al. Health, employment, and financial outcomes in workers with occupational asthma. $\mathrm{Br}$ J Ind Med 1993; 50: 491-496.

86 Orriols R, Drobnic ME, Munoz X, et al. Asma ocupacional por isocianatos: estudio de 21 pacientes [Occupational asthma due to isocyanates: a study of 21 patients]. Med Clin (Barc) 1999; 113: 659-662.

87 Merget R, Schulte A, Gebler A, et al. Outcome of occupational asthma due to platinum salts after transferral to low-exposure areas. Int Arch Occup Environ Health 1999; 72: 33-39.

88 Valentino M, Rapisarda V. Evoluzione dell'asma da isocianati in rapporto alla cessazione dell'esposizione: studio longitudinale su 50 soggetti [Course of isocyanate-induced asthma in relation to exposure cessation: longitudinal study of 50 subjects]. G Ital Med Lav Ergon 2002; 24: 26-31.

89 Padoan M, Pozzato V, Simoni M, et al. Long-term follow-up of toluene diisocyanate-induced asthma. Eur Respir J 2003; 21: $637-640$.

90 Lin FJ, Dimich-Ward H, Chan-Yeung M. Longitudinal decline in lung function in patients with occupational asthma due to western red cedar. Occup Environ Med 1996; 53: 753-756.

91 Marabini A, Siracusa A, Stopponi R, et al. Outcome of occupational asthma in patients with continuous exposure: a 3year longitudinal study during pharmacologic treatment. Chest 2003; 124: 2372-2376.

92 Perez Pimiento A, Bueso Fernandez A, Garcia Loria J, et al. Effect of omalizumab treatment in a baker with occupational asthma. J Investig Allergol Clin Immunol 2008; 18: 490-491.

93 Olivieri M, Biscardo CA, Turri S, et al. Omalizumab in persistent severe bakers' asthma. Allergy 2008; 63: 790-791.

94 Sastre J, Quirce S. Immunotherapy: an option in the management of occupational asthma? Curr Opin Allergy Clin Immunol 2006; 6: 96-100.

95 Rachiotis G, Savani R, Brant A, et al. Outcome of occupational asthma after cessation of exposure: a systematic review. Thorax 2007; 62: 147-152.

96 Pisati G, Baruffini A, Bernabeo F, et al. Rechallenging subjects with occupational asthma due to toluene diisocyanate (TDI), after long-term removal from exposure. Int Arch Occup Environ Health 2007; 80: 298-305.

97 Brant A, Zekveld C, Welch J, et al. The prognosis of occupational asthma due to detergent enzymes: clinical, immunological and employment outcomes. Clin Exp Allergy 2006; 36: 483-488.

98 Klusackova P, Pelclova D, Jindriska Levedova D, et al. Occupational asthma after withdrawal from the occupational allergen exposure. Ind Health 2006; 44: 629-638.

99 Labrecque M, Khemici E, Cartier A, et al. Impairment in workers with isocyanate-induced occupational asthma and removed from exposure in the province of Quebec between 1985 and 2002. J Occup Environ Med 2006; 48: 1093-1098.

100 Park HW, Kim DI, Sohn SW, et al. Outcomes in occupational asthma caused by reactive dye after long-term avoidance. Clin Exp Allergy 2007; 37: 225-230.

101 Park JW, Yang JY, Kim CW, et al. Avoidance therapy in reactive dye-induced occupational asthma: long-term follow-up. Ann Allergy Asthma Immunol 2006; 97: 551-556.

102 Yacoub MR, Lavoie K, Lacoste G, et al. Assessment of impairment/disability due to occupational asthma through a multidimensional approach. Eur Respir J 2007; 29: 889-896.

103 Munoz X, Gomez-Olles S, Cruz MJ, et al. Evolucion de la hiperrespuesta bronquial en pacientes con asma ocupacional por 
exposicion a sales de persulfato [Course of bronchial hyperresponsiveness in patients with occupational asthma caused by exposure to persulfate salts]. Arch Bronconeumol 2008; 44: 140-145.

104 Malo JL, Ghezzo H. Recovery of methacholine responsiveness after end of exposure in occupational asthma. Am J Respir Crit Care Med 2004; 169: 1304-1307.

105 Maghni K, Lemiere C, Ghezzo H, et al. Airway inflammation after cessation of exposure to agents causing occupational asthma. Am J Respir Crit Care Med 2004; 169: 367-372.

106 Piirila PL, Meuronen A, Majuri ML, et al. Inflammation and functional outcome in diisocyanate-induced asthma after cessation of exposure. Allergy 2008; 63: 583-591.

107 Sumi Y, Foley S, Daigle S, et al. Structural changes and airway remodelling in occupational asthma at a mean interval of 14 years after cessation of exposure. Clin Exp Allergy 2007; 37: 1781-1787.

108 Maestrelli P, De Marzo N, Saetta M, et al. Effects of inhaled beclomethasone on airway responsiveness in occupational asthma. Placebo-controlled study of subjects sensitized to toluene diisocyanate. Am Rev Respir Dis 1993; 148: 407-412.

109 Malo JL, Cartier A, Cote J, et al. Influence of inhaled steroids on recovery from occupational asthma after cessation of exposure: an 18-month double-blind crossover study. Am J Respir Crit Care Med 1996; 153: 953-960.

110 GINA. Global strategy for asthma management and prevention. NIH Publication. Bethesda, Global Initiative for Asthma, National Institute of Health, National Heart, Lung and Blood Institute, 2004. Report no. 02-3659.

111 Halbert RJ, Tinkelman DG, Globe DR, et al. Measuring asthma control is the first step to patient management: a literature review. J Asthma 2009; 46: 659-664.

112 Pisati G, Baruffini A, Zedda S. Toluene diisocyanate induced asthma: outcome according to persistence or cessation of exposure. Br J Ind Med 1993; 50: 60-64.

113 Burge PS. Occupational asthma in electronics workers caused by colophony fumes: follow-up of affected workers. Thorax 1982; 37: 348-353.

114 Paggiaro PL, Vagaggini B, Dente FL, et al. Bronchial hyperresponsiveness and toluene diisocyanate. Long-term change in sensitized asthmatic subjects. Chest 1993; 103: 1123-1128.

115 Bernstein DI, Karnani R, Biagini RE, et al. Clinical and occupational outcomes in health care workers with natural rubber latex allergy. Ann Allergy Asthma Immunol 2003; 90: 209-213.

116 Slovak AJ, Orr RG, Teasdale EL. Efficacy of the helmet respirator in occupational asthma due to laboratory animal allergy (LAA). Am Ind Hyg Assoc J 1985; 46: 411-415.

117 Taivainen AI, Tukiainen $\mathrm{HO}$, Terho EO, et al. Powered dust respirator helmets in the prevention of occupational asthma among farmers. Scand J Work Environ Health 1998; 24: 503-507.

118 Laoprasert N, Swanson MC, Jones RT, et al. Inhalation challenge testing of latex-sensitive health care workers and the effectiveness of laminar flow HEPA-filtered helmets in reducing rhinoconjunctival and asthmatic reactions. J Allerg Clin Immunol 1998; 102: 998-1004.

119 Muller-Wening D, Neuhauss M. Protective effect of respiratory devices in farmers with occupational asthma. Eur Respir J 1998; 12: 569-572.

120 Kongerud J, Rambjor O. The influence of the helmet respirator on peak flow rate in aluminum potroom. Am Ind Hyg Assoc J 1991; 52: 243-248.

121 Cote J, Kennedy S, Chan-Yeung M. Outcome of patients with cedar asthma with continuous exposure. Am Rev Respir Dis 1990; 141: 373-376.

122 Wilken D, Baur X, Barbinova L, et al. What are the benefits of medical screening and surveillance? Eur Respir Rev 2012 (in press).

123 Bryant DH, Boscato LM, Mboloi PN, et al. Allergy to laboratory animals among animal handlers. Med J Aust 1995; 163: 415-418.
124 Venables KM, Tee RD, Hawkins ER, et al. Laboratory animal allergy in a pharmaceutical company. Br J Ind Med 1988; 45: 660-666.

125 Kim YK, Son JW, Kim HY, et al. Citrus red mite (Panonychus citri) is the most common sensitizing allergen of asthma and rhinitis in citrus farmers. Clin Exp Allergy 1999; 29: 1102-1109.

126 Skjold T, Dahl R, Juhl B, et al. The incidence of respiratory symptoms and sensitisation in baker apprentices. Eur Respir $J$ 2008; 32: 452-459.

127 Walusiak J, Hanke W, Gorski P, et al. Respiratory allergy in apprentice bakers: do occupational allergies follow the allergic march? Allergy 2004; 59: 442-450.

128 Portengen L, Hollander A, Doekes G, et al. Lung function decline in laboratory animal workers: the role of sensitisation and exposure. Occup Environ Med 2003; 60: 870-875.

129 Renstrom A, Malmberg P, Larsson K, et al. Prospective study of laboratory-animal allergy: factors predisposing to sensitization and development of allergic symptoms. Allergy 1994; 49: 548-552.

130 Agrup G, Belin L, Sjostedt L, et al. Allergy to laboratory animals in laboratory technicians and animal keepers. Br J Ind Med 1986; 43: 192-198.

131 Baur X, Konig G, Bencze K, et al. Clinical symptoms and results of skin test., RAST and bronchial provocation test in thirty-three papain workers: evidence for strong immunogenic potency and clinically relevant "proteolytic effects of airborne papain". Clin Allergy 1982; 12: 9-17.

132 Gautrin D, Ghezzo H, Infante-Rivard C, et al. Natural history of sensitization., symptoms and occupational diseases in apprentices exposed to laboratory animals. Eur Respir J 2001; 17: 904-908.

133 Cockcroft A, Edwards J, McCarthy P, et al. Allergy in laboratory animal workers. Lancet 1981; 1: 827-830.

134 Juniper CP, Roberts DM. Enzyme asthma: fourteen years' clinical experience of a recently prescribed disease. J Soc Occup Med 1984; 34: 127-132.

135 De Zotti R, Bovenzi M. Prospective study of work related respiratory symptoms in trainee bakers. Occup Environ Med 2000; 57: 58-61.

136 Slovak AJ, Hill RN. Does atopy have any predictive value for laboratory animal allergy? A comparison of different concepts of atopy. Br J Ind Med 1987; 44: 129-132.

137 Suarthana E. Predicting occupational lung diseases. PhD thesis. Utrecht University, Utrecht, 2008; p. 127.

138 Meijer E, Grobbee DE, Heederik D. A strategy for health surveillance in laboratory animal workers exposed to high molecular weight allergens. Occup Environ Med 2004; 61: 831-837.

139 Suarthana E, Meijer E, Grobbee DE, et al. Predicting occupational diseases. Occup Environ Med 2009; 66: 713-714.

140 Gautrin D, Ghezzo H, Infante-Rivard C, et al. Long-term outcomes in a prospective cohort of apprentices exposed to high-molecularweight agents. Am J Respir Crit Care Med 2008; 177: 871-879.

141 Gautrin D, Infante-Rivard C, Ghezzo H, et al. Incidence and host determinants of probable occupational asthma in apprentices exposed to laboratory animals. Am J Respir Crit Care Med 2001; 163: 899-904.

142 Mapp CE, Dal Vecchio L, Boschetto $\mathrm{P}$, et al. Toluene diisocyanate-induced asthma without airway hyperresponsiveness. Eur J Respir Dis 1986; 68: 89-95.

143 Schumacher MJ, Tait BD, Holmes MC. Allergy to murine antigens in a biological research institute. J Allerg Clin Immunol 1981; 68: 310-318.

144 Balboni A, Baricordi OR, Fabbri LM, et al. Association between toluene diisocyanate-induced asthma and DQB1 markers: a possible role for aspartic acid at position 57. Eur Respir J 1996; 9: 207-210.

145 Horne C, Quintana PJ, Keown PA, et al. Distribution of DRB1 and DQB1 HLA class II alleles in occupational asthma due to western red cedar. Eur Respir J 2000; 15: 911-914. 
146 Meijer E, Grobbee DE, Heederik D. Detection of workers sensitised to high molecular weight allergens: a diagnostic study in laboratory animal workers. Occup Environ Med 2002; 59: 189-195.

147 Cullinan P, Tarlo S, Nemery B. The prevention of occupational asthma. Eur Respir J 2003; 22: 853-860.

148 Gannon PF, Berg AS, Gayosso R, et al. Occupational asthma prevention and management in industry-an example of a global programme. Occup Med (Lond) 2005; 55: 600-605.

149 Ruoppi P, Koistinen T, Susitaival P, et al. Frequency of allergic rhinitis to laboratory animals in university employees as confirmed by chamber challenges. Allergy 2004; 59: 295-301.

150 Kronqvist M, Johansson E, Pershagen G, et al. Increasing prevalence of asthma over 12 years among dairy farmers on Gotland, Sweden: storage mites remain dominant allergens. Clin Exp Allergy 1999; 29: 35-41.

151 Taiwo OA, Sircar KD, Slade MD, et al. Incidence of asthma among aluminum workers. J Occup Environ Med 2006; 48: 275-282.

152 Meijer E, Suarthana E, Rooijackers J, et al. Application of a prediction model for work-related sensitisation in bakery workers. Eur Respir J 2010; 36: 735-742.

153 Venables KM, Dally MB, Burge PS, et al. Occupational asthma in a steel coating plant. Br J Ind Med 1985; 42: 517-524.

154 Grammer LC, Shaughnessy MA, Henderson J, et al. A clinical and immunologic study of workers with trimellitic-anhydrideinduced immunologic lung disease after transfer to low exposure jobs. Am Rev Respir Dis 1993; 148: 54-57.

155 Merget R, Caspari C, Dierkes-Globisch A, et al. Effectiveness of a medical surveillance program for the prevention of occupational asthma caused by platinum salts: a nested case-control study. J Allerg Clin Immunol 2001; 107: 707-712.

156 Tarlo SM, Liss GM, Yeung KS. Changes in rates and severity of compensation claims for asthma due to diisocyanates: a possible effect of medical surveillance measures. Occup Environ Med 2002; 59: 58-62.

157 Tarlo SM, Liss GM. Can medical surveillance measures improve the outcome of occupational asthma? J Allerg Clin Immunol 2001; 107: 583-585.

158 Wild DM, Redlich CA, Paltiel AD. Surveillance for isocyanate asthma: a model based cost effectiveness analysis. Occup Environ Med 2005; 62: 743-749.

159 Suarthana E, Vergouwe Y, Nieuwenhuijsen M, et al. Diagnostic model for sensitization in workers exposed to occupational high molecular weight allergens. Am J Ind Med 2005; 48: 168-174.

160 Wilson JMG, Junger G. Principles and practice of screening for disease. Geneva, World Health Organization, 1968. Available from: http://whqlibdoc.who.int/php/WHO_PHP_34.pdf.

161 Heederik D, Henneberger PK, Redlich C. Primary prevention: exposure reduction, skin exposure and respiratory protection. Eur Respir Rev 2012 (in press).

162 Weeks JL, Levy BS, Wagner GR. Preventing occupational disease and injury. Washington DC, American Public Health Association, 1991.
163 Fisher R, Saunders WB, Murray SJ, et al. Prevention of laboratory animal allergy. J Occup Environ Med 1998; 40: 609-613.

164 Goodno LE, Stave GM. Primary and secondary allergies to laboratory animals. J Occup Environ Med 2002; 44: 1143-1152.

165 Sjostedt L, Willers S, Orbaek P, et al. A seven-year follow-up study of lung function and methacholine responsiveness in sensitized and non-sensitized workers handling laboratory animals. J Occup Environ Med 1998; 40: 118-124.

166 Vanhanen M, Tuomi T, Tiikkainen U, et al. Risk of enzyme allergy in the detergent industry. Occup Environ Med 2000; 57: 121-125.

167 Sorgdrager B, de Looff AJ, de Monchy JG, et al. Occurrence of occupational asthma in aluminum potroom workers in relation to preventive measures. Int Arch Occup Environ Health 1998; 71: 53-59.

168 Petsonk EL, Wang ML, Lewis DM, et al. Asthma-like symptoms in wood product plant workers exposed to methylene diphenyl diisocyanate. Chest 2000; 118: 1183-1193.

169 Fujita H, Sawada Y, Ogawa M, et al. [Health hazards from exposure to ortho-phthalaldehyde., a disinfectant for endoscopes., and preventive measures for health care workers]. Sangyo Eiseigaku Zasshi 2007; 49: 1-8.

170 Brisman J, Jarvholm B, Lillienberg L. Exposure-response relations for self reported asthma and rhinitis in bakers. Occup Environ Med 2000; 57: 335-340.

171 Renstrom A, Mattsson ML, Blidberg K, et al. Nasal air sampling for measuring inhaled wheat allergen in bakeries with and without facemask use. J Occup Environ Med 2006; 48: 948-954.

172 Liu Y, Stowe MH, D B, Woskie SR, et al. Respiratory protection from isocyanate exposure in the autobody repair and refinishing industry. J Occup Environ Hyg 2006; 3: 234-249.

173 Grammer LC, Ditto AM, Tripathi A, et al. Prevalence and onset of rhinitis and conjunctivitis in subjects with occupational asthma caused by trimellitic anhydride (TMA). J Occup Environ Med 2002; 44: 1179-1181.

174 Bateman ED, Hurd SS, Barnes PJ, et al. Global strategy for asthma management and prevention: GINA executive summary. Eur Respir J 2008; 31: 143-178.

175 Beach J, Rowe BH, Blitz S, et al. Diagnosis and management of work-related asthma. Evidence report/technology assessment (Summary) 2005; 1-8. Available from: www.ahrq.gov/clinic/ epcsums/asthworksum.pdf

176 Newman Taylor A, Nicholson PJ, Cullinan P, et al. Guidelines for the prevention, identification, \& management of occupational asthma: evidence review \& recommendations. www.bohrf.org. uk/downloads/asthevre.pdf Date last updated: 2004. Date last accessed: January 16, 2012.

177 Henneberger P, Redlich CA. Work-exacerbated asthma. In: Sigsgaard T, Heederik D, eds. Occupational Asthma. Basel, Birkhäuser, 2010; pp. 89-100.

178 Henneberger PK, Redlich CA, Callahan DB, et al. An official American Thoracic Society statement: work-exacerbated asthma. Am J Respir Crit Care Med 2011; 184: 368-378. 